\title{
Anosmia congênita associada à hipospádia: relato de caso
}

\author{
Congenital anosmia associated with hypospadia: a case report
}

Guilherme Jardim Okazaki', Giovana Moretti', Maria Claudia Bicudo², Fábio José Nascimento², Fernando Veiga Angélico Junior', Priscila Bogar Rapoport ${ }^{1}$

\begin{abstract}
Resumo
Introdução: A incidência de distúrbios olfatórios nos Estados Unidos da América é de cerca de 200 mil pacientes por ano, sendo as doenças sinusais as causas mais comuns. A anosmia congênita é rara e pode ocorrer como parte de uma síndrome ou como anosmia isolada. 0 objetivo deste trabalho é relatar um caso raro de anosmia congênita associada à hipospádia. Descrição do caso: Paciente masculino com 20 anos de idade e quadro de anosmia congênita, apresentando gustação e sensibilidade olfatória para odores irritantes preservadas. Refere hipospádia operada aos 13 anos de idade. Negava antecedentes familiares de anosmia. Apresentava exame otorrinolaringológico e nasofibroscopia sem alterações. Ao exame neurológico constatouse anosmia pelo Cross Culture Smell Test. Ao exame geniturinário, apresentava orifício fistuloso em face ventral de terço médio do pênis, testículos tópicos e de tamanho normal, e desenvolvimento normal dos caracteres sexuais secundários. Observou-se, na tomografia computadorizada dos seios paranasais, presença de concha média bolhosa à esquerda. A ressonância magnética apresentava-se dentro dos padrões de normalidade. Uma análise hormonal foi realizada, cujos resultados foram: hormônio luteinizante de $5,02 \mathrm{mUl} / \mathrm{mL}$, Hormônio folículo-estimulante de 0,8 $\mathrm{mUI} / \mathrm{mL}$ e testosterona total de $887 \mathrm{ng} / \mathrm{dL}$. Discussão: 0 relato deste caso é importante pela existência de apenas dois casos relatados na literatura de anosmia congênita associada à hipospádia. 0 relato de um novo caso e da associação da anosmia com outras anormalidades, como a hipospádia, pode auxiliar na aquisição de novos conhecimentos sobre 0 assunto e a despertar interesse na descoberta de algum fator etiológico comum às duas anormalidades.
\end{abstract}

Palavras-chave: Transtornos do olfato; hipospádia; doenças do nervo olfatório.

\begin{abstract}
Introduction: The incidence of olfactory disorders in the United States is approximately 200,000 patients per year. Sinus diseases are the most common causes. The congenital anosmia is rare and may occur as part of a syndrome or isolated. The purpose of this paper is to report a case of congenital anosmia associated with hypospadia. Case report: Male, 20 years old, reporting congenital anosmia. The taste and olfactory perception for irritant odors were preserved. He was submitted to hypospadia repair surgery at the age of 13 years old. Family history of anosmia was negative. Otolaryngologyc exam and nasofibroscopy were normal. In the neurologic exam, anosmia was determined by Cross Culture Smell Test. Genitourinary exam showed: fistular orificium in ventral face of medium third section of penis, topic and normal size testicles and full development of secondary sexual characters. On computed tomography of paranasal sinuses, a concha bullosa was observed on the left. The magnetic resonance was normal. Hormonal tests: $\mathrm{LH}$ $5.02 \mathrm{mUl} / \mathrm{mL}$, FSH $0.8 \mathrm{mUl} / \mathrm{mL}$ and total testosterone $887 \mathrm{ng} / \mathrm{dL}$. Discussion: This case report is important because there are only two cases reported in the literature about congenital anosmia associated with hypospadia. The report of a new case and the association of anosmia with others abnormalities such as hypospadia may lead to additional knowledge about the subject and may raise interest on the discovery of common etiological factors of these abnormalities (anosmia and hypospadia).
\end{abstract}

Keywords: Olfaction disorders; hypospadias; olfactory nerve diseases.

Recebido: 6/2/2009

Revisado: $6 / 3 / 2010$

Aprovado: $14 / 10 / 2010$

\footnotetext{
Trabalho realizado no Hospital Estadual Mário Covas, Santo André (SP), Brasil

Disciplina de Otorrinolaringologia da Faculdade de Medicina do ABC (FMABC), Santo André (SP), Brasil

2 Disciplina de Urologia da Faculdade de Medicina do ABC (FMABC), Santo André (SP), Brasil

Endereço para correspondência: Guilherme Jardim Okazaki - Avenida Príncipe de Gales 821 - Vila Príncipe de Gales - CEP 09060-650 - Santo André (SP), Brasil e-mail: guilhermejardim@hotmail.com.
} 


\section{Introdução}

A incidência de distúrbios olfatórios nos Estados Unidos da América é de cerca de 200 mil pacientes por ano, sendo as doenças nasosinusais as causas mais comuns ${ }^{1}$.

A anosmia se caracteriza pela ausência da sensação olfatória, ou seja, incapacidade de sentir odores ${ }^{2}$, podendo ser congênita ou adquirida. A anosmia congênita isolada é rara e se relaciona a alterações do epitélio olfatório ou aplasia do nervo, trato ou bulbo olfatório ${ }^{3}$. Pode ocorrer como parte de uma síndrome ou isoladamente. A forma de anosmia congênita mais comum é a encontrada na Síndrome de Kallmman (SK) 3 .

Esta síndrome resulta de um defeito na migração dos axônios neurais responsáveis pela secreção do GnRH ( hormônio liberador de gonadotrofinas) pelo hipotálamo, levando à hipoplasia do bulbo olfatório e ao defeito na secreção de GnRH. A maioria dos casos é esporádica, mas pode ser familiar. Classicamente, apresenta-se como hipogonadismo hipogonadotrófico primário associado à hiposmia ou anosmia, podendo se associar a outras anomalias e alterações de linha média. O fenótipo é bastante variado, sendo que na SK familiar, alguns pacientes portadores de mutações dos genes PROKR2, PROK2 e FGFR1 apresentaram hipogonadismo isolado ou anosmia isolada. Parentes de pacientes com SK também podem apresentar anosmia isolada ${ }^{2}$.

A hipospádia é um defeito congênito da uretra, sendo sua etiologia pouco conhecida, provávelmente multifatorial (hormonal e ambiental) ${ }^{4}$. A associação com SK é muito rara, havendo apenas dois artigos na literatura que observaram tal associação ${ }^{5,6}$. O fato de ser um defeito de linha média pode justificar essa associação, que também pode ser suposta, pois ambas as doenças são hormônio dependentes e afetam a genitália externa ${ }^{6}$.

A pesquisa de fatores envolvidos na anosmia é realizada através de anamnese, exame físico, nasofibroscopia e exames complementares. A endoscopia nasosinusal é realizada para excluir causas comuns de diminuição do olfato, como pólipos ou rinossinusites. Os testes de imagem incluem a tomografia computadorizada (TC) e a ressonância magnética (RM). A RM de crânio deve enfatizar o hipotálamo-hipófise, a fossa craniana anterior, o trato e o bulbo olfatório para excluir tumor de sistema nervoso central ${ }^{7}$.

Este trabalho teve como objetivo relatar um caso raro de anosmia congênita associada à hipospádia e revisar a literatura.

\section{Descrição do caso}

Paciente do sexo masculino, pardo, 20 anos de idade, com quadro de anosmia desde o nascimento, negava reconhecimento prévio de odores, sugerindo, portanto, uma anosmia congênita. A gestação ocorreu dentro da normalidade, e a mãe não foi exposta a nenhum fator que pudesse estar relacionado à gênese da hipospádia. Refere prurido nasal e espirros em salva esporadicamente. A gustação e a sensibilidade olfatória para odores irritantes permaneciam preservadas. Negava outras queixas nasais ou otorrinolaringológicas. Não apresentava antecedentes familiares de anosmia ou síndrome de Kallmann. Refere cirurgia para correção de hipospádia há sete anos. O paciente evoluiu com fístula urinária no pós-operatório tardio, sendo novamente submetido a procedimento cirúrgico em maio de 2008.

Ao exame físico otorrinolaringológico, não foram encontradas alterações e a nasofibroscopia flexível não evidenciou nenhuma anormalidade. O exame neurológico evidenciou apenas anosmia, que foi verificada utilizando-se o Cross Culture Smell Test, um teste de sensibilidade olfatória com 12 tipos de odores, incluindo: chocolate, abacaxi, tabaco, gasolina, rosas, sabão, aguarrás, limão, acetona, canela, cebola e banana ${ }^{8}$. A visão do paciente foi ocluída para a realização do teste e cada narina foi testada separadamente. O paciente foi questionado sobre a identificação das substâncias e se eram irritativas. Verificouse apenas sensibilidade irritativa para gasolina e acetona, não sendo o paciente capaz de identificar os diferentes tipos de odores em ambas as narinas, portanto o escore do teste foi zero. Não houve diferença de sensibilidade olfatória entre as duas narinas.

O exame do aparelho geniturinário revelou a presença de orifício fistuloso em face ventral de terço médio do pênis (Figura 1), testículos

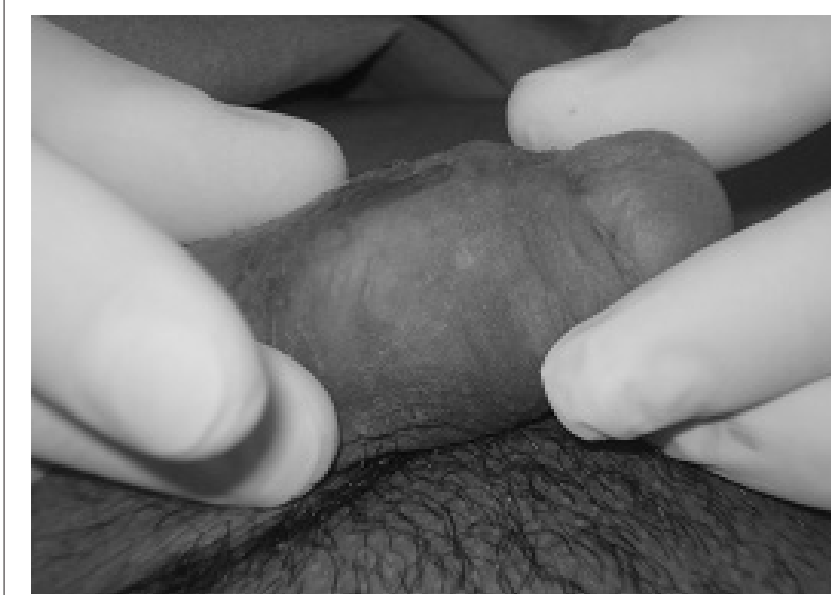

A

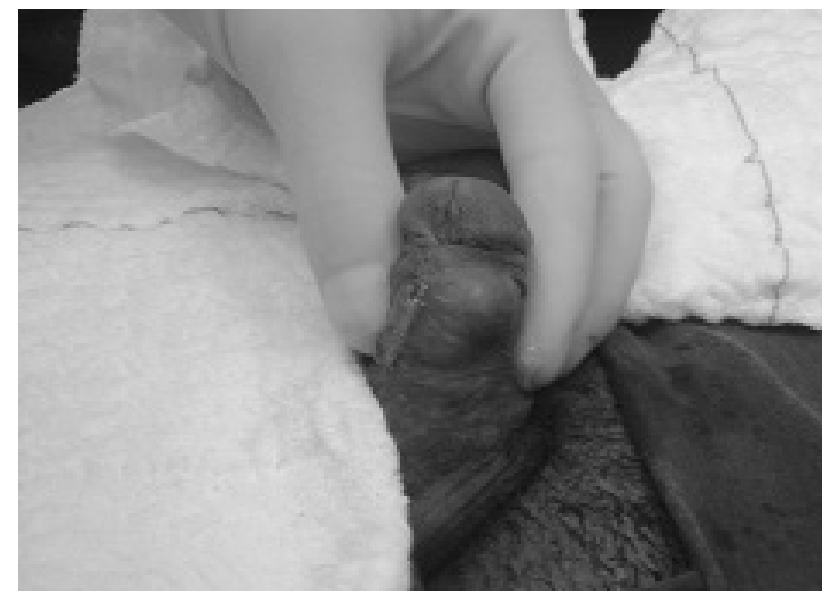

B

Figura 1 - (A) Meato hipospádico estenótico; (B) identificação de trajeto fistuloso após injeção de xilocaína gel. 


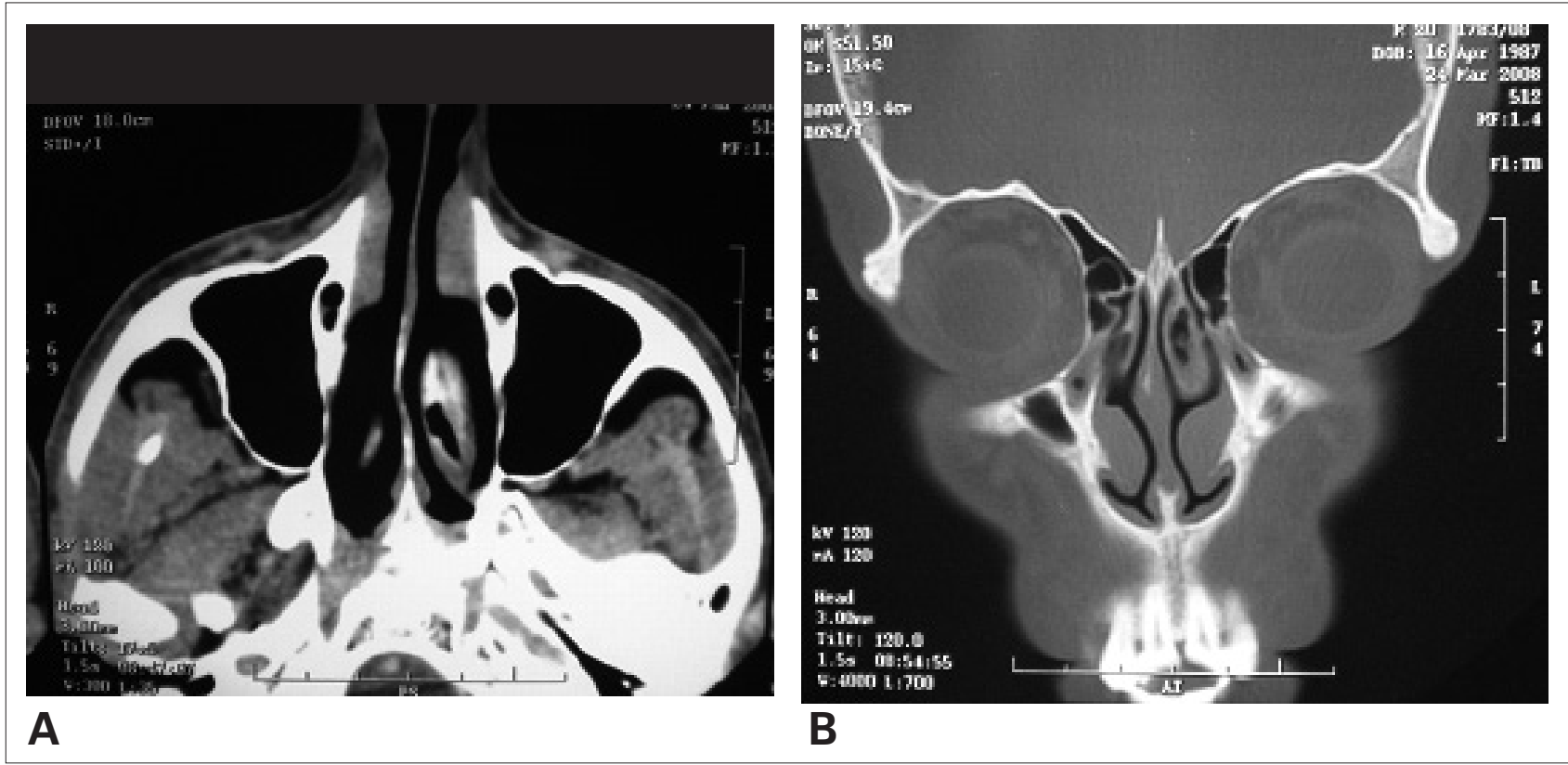

Figura 2 - Tomografia computadorizada de seios paranasais. (A) Corte axial evidenciando concha média bolhosa à esquerda; (B) corte coronal evidenciando concha média bolhosa à esquerda.

tópicos e de tamanho normal e desenvolvimento normal de caracteres sexuais secundários. Atualmente, o paciente está em acompanhamento com a equipe de urologia.

Não foi encontrada nenhuma outra anomalia ou malformação no paciente.

Foi realizada tomografia computadorizada com contraste dos seios paranasais em projeção axial e coronal com cortes de $3 \mathrm{~mm}$ de espessura, com achado de concha média bolhosa à esquerda (Figura 2). A ressonância nuclear magnética foi realizada pela técnica de fast spinecho com sequências ponderadas em T1, T2 e Flair e T1 pós-contraste endovenoso paramagnético, nos planos axial, sagital e coronal, com saturação para gordura apresentando parâmetros dentro da normalidade. Ultrassonografia de rins e vias urinárias sem alterações.

Realizou-se avaliação hormonal: hormônio luteinizante (LH): $5,02 \mathrm{mUI} / \mathrm{mL}(1,5$ a $9,3 \mathrm{mUI} / \mathrm{mL})$, hormônio folículo-estimulante (FSH): $0,8 \mathrm{mUI} / \mathrm{mL}(1,4$ a $18,1 \mathrm{mUI} / \mathrm{mL})$, prolactina: $6,03 \mathrm{ng} / \mathrm{mL}$ $(2,1$ a $17,7 \mathrm{ng} / \mathrm{mL})$ e testosterona total: $887 \mathrm{ng} / \mathrm{dL}(241 \mathrm{a} 827 \mathrm{ng} / \mathrm{dL})$.

O presente estudo foi aprovado pelo Comitê de Ética em Pesquisa da Faculdade de Medicina do ABC, sob o protocolo n 007/2009.

\section{Discussão}

A anosmia congênita isolada é rara, estando relacionada a alterações do epitélio olfatório ou aplasia do nervo, trato ou bulbo olfatório ${ }^{3}$, e o exame físico e teste olfatório são importantes para a sua caracterização. Leopold et al. estudaram 22 pacientes com anosmia congênita e observaram, por meio de testes olfatórios, que eles não tinham capacidade de detectar odores via olfatória, porém muitos apresentaram a capacidade de pelo menos detectar odores via trigeminal'. Este fato também foi obser- vado no caso relatado, pois o paciente apresentava sensibilidade olfatória para odores irritantes preservada, conforme verificado pelo Cross Culture Smell Test ${ }^{8}$. Este teste é confiável e permite testar a função olfatória em menos de 5 minutos utilizando 12 tipos de odores universais conhecidos por pessoas da América do Norte, Ásia, Europa e América do Sul ${ }^{8}$. A sensibilidade para odores irritantes é uma função do nervo trigêmeo.

Aiba et al. estudaram nove pacientes com anosmia congênita e observaram que sete deles apresentavam alterações de bulbo, trato e sulco olfatório ou de giro reto, e os outros dois pacientes tinham morfologia olfatória normal. Nestes casos, a anosmia sensório-neural não pode ser afastada ${ }^{10}$. Neste relato, não havia alterações morfológicas da via olfatória.

Observou-se anosmia com ausência de hipogonadismo hipogonadotrófico, não sendo, portanto, foi definido como um caso de síndrome de Kallmann clássica ${ }^{11}$. Parentes de pacientes com SK podem apresentar anosmia isolada, hipogonadismo isolado ou retardo mental. Na SK familiar, pacientes portadores de mutações dos genes PROKR2, PROK2 e FGFR1 apresentaram hipogonadismo isolado ou anosmia isolada ${ }^{2,12,13}$. O paciente relatado não tem nenhum parente conhecido com SK.

A síndrome de Kallmann pode estar associada a alterações geniturinárias como criptorquidia, agenesia ou displasia renal, genitália externa infantil ${ }^{3}$ e, mais raramente, a hipospádia ${ }^{5,6}$.

A hipospádia é um defeito congênito da uretra masculina, estando a abertura do meato uretral na face ventral do pênis. A etiologia da hipospádia é pouco conhecida, sendo provavelmente multifatorial (genética hormonal e ambiental) ${ }^{5}$. Há várias teorias para o seu aparecimento, como uma deficiência de testosterona entre a $9^{\mathrm{a}}$ e a $13^{\mathrm{a}}$ semana de gestação, nas quais ocorre a formação da uretra ${ }^{4}$.

Há uma síndrome autossômica dominante descrita na literatura, a Síndrome G, na qual há malformações da linha média, incluindo hiper- 
telorismo, telecanto, hipospádia e fenda labial e palatina ${ }^{11}$. Cordero et al. descreveram um caso de uma mãe de um menino com a síndrome; além de hipertelorismo e telecanto, ela tinha anosmia, uma característica não descrita previamente nesta síndrome ${ }^{11}$. No presente relato, não havia nenhum outro defeito de linha média além da hipospádia no paciente.

$\mathrm{Na}$ literatura analisada, foram encontrados dois casos de pacientes masculinos com SK associada com hipospádia, um relatado por Ponticelli $i^{5}$ e outro por Kurzrock ${ }^{6}$. O que diferencia o presente relato dos casos da literatura é o fato de a anosmia congênita ser isolada, isto é, não associada ao hipogonadismo hipogonadotrófico e, dessa forma, não caracterizada como manifestação da síndrome de Kallmann clássica. Além disso, a idade ao diagnóstico do paciente foi maior do que a reportada na literatura.
Aparentemente, não há nenhum fator confirmado que associe hipospádia à anosmia congênita isolada. Portanto, a coexistência das duas malformações pode ser mais um acaso da natureza do que uma associação sindrômica.

O relato deste caso é de fundamental importância pela existência de apenas dois casos na literatura sobre anosmia congênita associada à hipospádia, sendo ambos relacionados à síndrome de Kallmann e não à anosmia isolada.

Pelo fato de a anosmia congênita ser rara, o relato de um novo caso e da associação da anosmia com outras anormalidades, como a hipospádia, pode auxiliar na aquisição de novos conhecimentos sobre o assunto e a despertar interesse na descoberta de algum fator desencadeante comum às duas anormalidades.

\section{Referências}

1. Damm M, Temmel A, Welge-Lüssen A, Eckel HE, Kreft MP, Klussmann JP, et al. Olfactory disfunction. Epidemiology and therapy in Germany, Austria and Switzerland. HNO. 2004;52(2):112-20.

2. Ribeiro RS, Abucham J. Síndrome de Kalmann: uma revisão história, clínica e molecular. Arq Brás Endocrinol Metab. 2008;52(1):8-17.

3. Ghadami M, Majidzadeh-A K, Morovvati S, Damavandi E, Nishimura G, Komatsu K, et al. Isolated congenital anosmia with morphologically normal olfactory bulb in two Iranian families: a new clinical entity? Am J Med Genet. 2004;127(3):307-9.

4. Macedo Júnior A, Srougi M. Hipospádias. Rev Assoc Med Bras. 1998;44(2):141-5

5. Ponticelli C, Frosini P, Masi L. La síndrome di Kallmann. A propósito di due personali osservazioni. Acta Otorhinolaryngol Ital. 1991;11(6):603-8.

6. Kurzrocke EA, Delair S. Hypospadias and Kallmann's syndrome: Distinction between morphogenesis and growth of the male phallus. J Pediatric Urol. 2006;2(5):515-7.

7. Schmidt VB, Roithmann R, Corleta HVE, Capp E. Hipogonadismo hiponadotrófico e anosmia: síndrome de Kallmann. Rev Bras Otorrinolaringol. 2001;67(6):880-4.

8. Doty RL, Marcus A, Lee WW. Development of the 12-item Cross-Cultural Smell Identification Test (CC-SIT). Laryngoscope. 1996;106(3):353-6.

9. Leopold DA, Hornung DE, Schwob JE. Congenital lack of olfactory ability. Ann Otol Rhinol Laryngol. 1992;101(3):229-36.

10. Aiba T, Inoue $Y$, Matsumoto K, Shakudo M, Hashimoto K, Yamane H. Magnetic resonance imaging for diagnosis for congenital anosmia. Acta Otolaryngol. 2004;124(Suppl 554):50-4.

11. Cordero JF, Holmes LB. Phenotypic overlap of the BBB and G syndromes. Am J Med Genet. 1978;2(2):145-52.

12. Trarbach EB, Costa EM, Versiani B, de Castro M, Baptista MT, Garmes HM, et al. Novel fibroblast growth factor receptor 1 mutations in patients with congenital hypogonadotropic hypogonadism with and without anosmia. $J$ Clin Endocrinol Metab. 2006;91(10):4006-12.

13. Silveira LF, Trarbach EB, Latronico AC. Genetics basis for GnRH-dependent pubertal disorders in humans. Mol Cell Endocrinol. 2010;324(1-2):30-8. 